\title{
Kumar Oynama Bozukluğunda Bilişsel Davranışçı Terapinin Etkinliği Üzerine Sistematik Bir Derleme
}

\section{A Systematic Review of the Effectiveness of Cognitive Behavioral Therapy in Gambling Disorder}

\author{
Ayşe Buran 1iD \\ 1. Yakın Doğu Üniversitesi, Psikoloji Bölümü, Lefkoşe, Kıbrıs
}

\begin{abstract}
Due to the increasing number of gambling disorders in recent years, various treatment methods have emerged by mental health professionals. Although various approaches address this problem, there are not many studies on the effectiveness of these approaches. The aim of this study is to investigate the effectiveness of cognitive behavioral therapy applied to gambling disorder in the literature. In this study using the PRISMA method, gambling disorder and cognitive behavioral therapy approaches were scanned in electronic databases and 10 studies were included in the systematic review. All studies used cognitive behavioral therapy (CBT) methods. There was no statistically significant difference between the CBT techniques used in the same study. All CBT approaches were found to be effective in the treatment of gambling, and were also effective in non-gambling secondary psychopathological problems. While the studies had a mean follow-up of 6 months, gambling shift behavior was generally observed in the first month of the therapy process. Even though all studies applied different methods, various solutions were provided to gambling disorder and secondary problems. The systematic reviews of studies on gambling disorder will provide more use of therapy methods especially in gambling disorder. In multidimensional examination and treatment of gambling disorder, not only psychopharmacological therapies but also eclectic approaches should be shaped with the addition of these approaches.
\end{abstract}

Keywords: Gambling disorder, addiction, cognitive behavioral psychotherapy

Öz

Kumar oynama bozukluğunun son yıllarda giderek artması nedeniyle bu konuda ruh sağlı̆ı çalışanları tarafından çeşitli tedavi yöntemleri ortaya çıkmaya başlamışır. Her ne kadar çeşitli yaklaşımlar bu sorunu ele alıyor olsa da bu yaklaşımların etkinliğine dair çok fazla çalışma bulunmamaktadır. Bu çalışmanın amacı alanyazında kumar oynama bozukluğuna uygulanan bilişsel davranışçı terapi çalışmalarını derleyerek etkililiğini araştırmaktır. PRISMA yönteminin kullanıldığı bu çalışmada kumar oynama bozukluğu ve bilişsel davranışçı terapi yaklaşımları elektronik veri tabanlarında taranmış ve tam metnine ulaşılan 29 çalışmadan 10 çalışma sistematik derlemeye dahil edilmiştir. Derlenen tüm çalışmalar bilişsel davranışç terapi (BDT) yöntemini kullanmıştır. Araşıımalarda farklı BDT yöntemleri aynı çalışmada kullananlar bu teknikler arasında istatistiksel olarak anlamlı bir farkılık olmadığnı tespit etmiştir. Tüm BDT yaklaşımlarının kumar tedavisinde etkin olduğu, bu yaklaşımların ayrıca kumar harici ikincil psikopatolojik sorunlarda da etkili olduğu görülmüştür. Çalışmaların ortalama 6 aylık bir takip sürecine sahip olduğu görülürken, kumara kayma davranışının genellikle terapi sürecinin ilk bir ayında yaşandığı çalışmalarda gözlemlenmiş̧tir. Araşıırmaya dahil edilen tüm çalışmalar farkı BDT teknikleri uygulasa da, bu çalışmalarda kumar oynama bozukluğu ve ikincil sorunlara çeşitli çözümler sunulmuştur. Kumar oynama bozukluğu ile ilgili yapılan çalışmaların bilimsel olarak derlenmesi, terapi yöntemlerinin özellikle kumar oynama bozukluğunda daha fazla kullanılmasını sağlayacaktır. Kumar oynama bozukluğunun çok boyutlu incelenmesi ve tedavisinde sadece psikofarmakolojik tedavilerin değil, bu yaklaşımların da eklenmesiyle eklektik bir bakış açısılla tedavilerin şekillenmesi gerekmektedir. Anahtar kelimeler: Kumar oynama bozukluğu, bağımlılık, bilişsel davranışçı terapi 


\section{Giriş}

Kumar oyunları, genellikle sosyal aktivite olarak kabul edilen bir eğlence aracı olarak görülmektedir (1). Fakat, kumara ilişkin yaşanılan olumsuz durumlara rağmen kumar oynamaya devam etmek, bu durumun problemli bir davranışa dönüşmesine sebep olabilmektedir (2). Ruh Sağlığı Tanı Kitabına (DSM) ilk olarak dürtü kontrol bozukluğu olarak giren kumar oynama davranışı (3), sonrasında oynayan bireyin yaşadığı ciddi kişisel ve sosyal sonuçlara rağmen (örn: borca girme, aile ilişkilerinde sorun yaşama vs.) kumar oynama durumundan vazgeçilememesi durumu olarak tanımlanmış ve Patolojik Kumar Bozukluğu olarak isimlenmiştir (4). DSM-V ile birlikte kumar oynama bozukluğu (KOB) madde ile ilişkili olmayan bağımlılıklar sınıflamasında yer alan ilk davranış bağımlıı̆ı olmuştur (5). Bu sınıflandırma ile birlikte kumarla aşırı uğraş, kumarda maddi kayıplara rağmen oynamaya devam etme, ve aileye ya da arkadaşlara kumara dair yalan söylemek kumar bağımlılı̆̆ kriterleri arasında yer almaya başlamıştır (5).

KOB'nun toplumda görülme sıkığının artmasıyla kumar ile ilişkili bozuklukların çözümünde profesyonel desteğe başvurunun arttığı görülmektedir $(6,7)$. KOB tedavisinde çok boyutlu bir tedavi planı oluşturulmasının tedavinin etkinliğini artıracağı ifade edilmekte ve psikofarmakoloji, psikoterapi, finansal, eğitimsel ve kendine yardım programları gibi farklı tedavi uygulamalarının KOB ile mücadelede kullanılması önerilmektedir (8). Bu tedavilerde yer alan psikoterapi teknikleri incelendiğinde bilişsel-davranışçı ya da psikanalitik yaklaşım, "Adsız Kumarbazlar" gibi kendine yardım grupları, grup terapileri, motivasyonel ve eklektik terapi yaklaşımlarının terapi süreçlerinde kullanıldığı görülmüştür (9-11). Her ne kadar kumarla ilişkili tedavi yöntemleri artmış olsa da bu yöntemlerin etkinliğine dair destekleyici çalışmaların az olduğu belirtilmektedir (12,13). KOB üzerinde etkinliği incelenen terapi yaklaşımları arasında özellikle bilişsel davranışçı terapinin (BDT) kumar oynama bozukluğu üzerinde etkili olduğu önceki çalışmalarca bildirilmiştir $(14,15)$.

Bilişsel davranışçı yaklaşım, patolojik kumar oynamayı öğrenilmiş uyumsuz davranış olarak görmektedir, bu nedenle BDT, bu davranışı öğrenme ilkelerinden türetilen tekniklerle değiştirmeye çalışır (16). BDT teknikleri arasında, kaçınma terapisi, sistematik duyarsılaştırma, maruz kalma, hayali gevşeme ve uyaran kontrolü gibi terapötik yaklaşımlar yer almaktadır (17). BDT teknikleri arasında yer alan pekiştirme tekniği KOB tedavisinde kumar oynama davranışını ortadan kaldırmak için kumar oynama davranış olmayan etkinlikleri pekiştirme ve ödevlerle bu davranışı geliştirme şeklinde bu kumara yönelik BDT terapilerinde sıkıkla kullanılmaktadır (18). KOB'na yönelik BDT terapileri bireysel olabileceği gibi grupla terapi şeklinde de yürütülebilmektedir $(19,20)$.

Türkçe alanyazında kumar bağımlılığının tedavisini inceleyen sistematik bir derlemeye rastlanmamıştır. Gün geçtikte önemli bir halk sağlığı sorunu olan kumar bağımlılı̆ında etkli olan psikoterapi yaklaşımlarının bilinmesi önem arz etmektedir. Bu sistematik derlemede kumar oynama bozukluğunun tedavisinde kullanılan BDT'nin etkinliği araştırımaktadır.

\section{Yöntem}

Araştırmada KOB tedavisinde kullanılan BDT'ini araştıran çalışmalar PRISMA protokolüne uygun bir şekilde derlenmiştir (21). Bu doğrultuda Mart-Eylül 2020 tarihleri arasında 2010 ve 2020 yılları arasında yayımlanmış, tam metni Türkçe ve İngilizce olan araştırma makalelerinin taranması uygun görülmüştür. Araştırmada Dergipark, Scopus, ScienceDirect, Wiley Online Library, PubMed, Ebscohost, PsycINFO gibi elektronik veritabanları araştırmaya dahil edilmiştir. Veritabanı aramalarında "kumar bağımlıı̆ı", "patolojik kumar", "psikoterapi", "tedavi yöntemleri", "bilişsel davranışçı terapi" gibi anahtar kelimeler İngilizce ve Türkçe olarak taranmıştır. Ayrıca araştırmacı tarafından ilgili makalelerin kaynakçaları taranarak konu ile ilişkili olan ve bu veritabanlarında bulunmayan çalışmalar da incelenmiştir.

Araştırmaya kabul kriterleri olarak dil (Türkçe/ İngilice), yayımlanma tarihi (2010-2020 yılları arası), araştırma teknikleri (nicel araştırma yöntemi), ve psikoterapi yöntemleri ile ilişkili değişkenler (KOB ve BDT) 
dikkate alınarak belirlenmiştir. Araştırmada DSM kriterlerine göre KOB tanısı almış bireylerle yapılan BDT tekniklerine dayalı çalışmalar dahil edilmiş̧ir. Araştırmada KOB ile ilgili sadece psikofarmakolojik tedavi yöntemlerini kullanan araştırmalar ve geçerliliği kanıtlanmamış terapi teknikleri dışlanmıştır. Araştırmada vaka çalışmaları ve takip çalışmaları olmayan araştırma çalışmaları araştırma dışında tutulmuştur. Araştırma sürecinde tam metnine ulaşılmamış çalışmalar da araştırmaya dahil edilmemiştir.

\section{Bulgular}

Araştırnaya toplam 10 çalışma dahil edilmiştir. Şekil 1'de çalışmaya dahil edilen çalışmalar PRISMA akış diyagramı şeklinde verilmiştir. Araştırmada yer alan arama kriterlerine uymayan, psikofarmakolojik araştırmalar, olgu sunumları ve takip çalışması olmayan çalışmalar tam metinlerine ulaşılmasına rağmen dışlanmıştır.

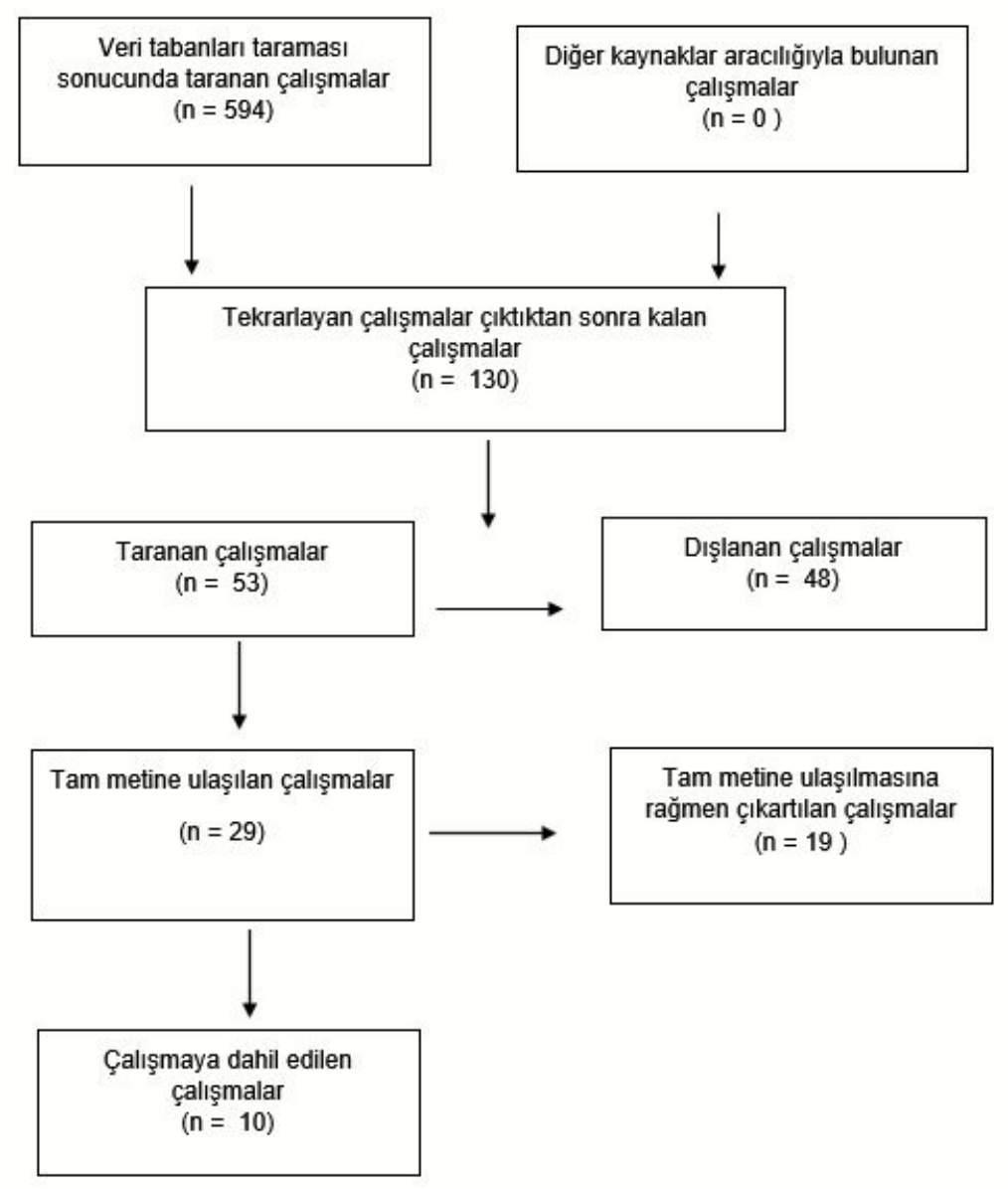

\section{Şekil 1. Çalışmanın PRISMA akış diyagramı}

Araştırmalara dair karakteristik özellikler Tablo 1'de verilmiştir. İncelenen çalışmaların örneklemleri $n=35$ ve $n=556$ arasında değişmektedir. Yaş aralığının en düşük 32.2 ve en yüksek 39 olan çalışmalar İspanya, İsveç, Avustralya ve Amerika gibi farklı ülkelerde gerçekleştirilmiştir. Taranan çalışmaların hepsinde KOB dışında ikincil değişkenler de çalışımıştır. Bu değişkenler arasında depresyon ve anksiyete en fazla çalışılan konular olmuştur. Bu çalışmalarda en kısa takip çalışması bir ay en fazla 36 ay olmakla birlikte yaklaşık 6 aylık takip süreci olduğu görülmektedir. Derlenen çalışmalara ait demografik bilgiler tablo 1de verilmiştir.

Incelenen çalışmalarda grup terapi, bireysel görüşme, motivasyonel terapi, duyarsızlaştırma teknikleri, internet temelli terapi gibi BDT'ye ait farkı tekniklerin kullanıldığı görülmüştür. Araştırmalarda kumarın tanımlanması için kullanılan ölçekler arasında \%40 ile en fazla tercih edilen ölçek NODS ölçeğidir. 
Tablo 1. Çalışma özellikleri ve terapi sonuçları

\begin{tabular}{|c|c|c|c|c|c|c|c|c|}
\hline Kaynak & Ülke & $\begin{array}{l}\text { (n, \% } \\
\text { erkek, } \\
\text { yaş) }\end{array}$ & $\begin{array}{l}\text { Terapi } \\
\text { yaklaşımı }\end{array}$ & $\begin{array}{l}\text { Seans } \\
\text { Süresi }\end{array}$ & $\begin{array}{l}\text { Taki } \\
\mathrm{p}\end{array}$ & $\begin{array}{l}\text { Kumara } \\
\text { Ilisskin } \\
\text { ölçüm }\end{array}$ & $\begin{array}{l}\text { Kumar } \\
\text { dışı } \\
\text { ölçüm }\end{array}$ & Tedavi etkinliği \\
\hline (22) & İspanya & $\begin{array}{l}566 \\
\% 92,2 \\
43.5\end{array}$ & $\begin{array}{l}\text { Bireysel } \\
\text { BDT }\end{array}$ & $\begin{array}{l}1-2 \\
\text { Haftada } \\
1,6 \text { ay }\end{array}$ & $\begin{array}{l}3, \\
9, \\
21 \\
\text { ay }\end{array}$ & NODS & $\begin{array}{l}\text { TCl-R } \\
\text { MCMI-III }\end{array}$ & $\begin{array}{l}\text { \%14.1 nüks, } \\
\% 11.5 \text { 'i } 6 \text { aylık } \\
\text { terapi süresinde } \\
\text { Yalnızlık ve az } \\
\text { para harcamış } \\
\text { olmak risk faktörü } \\
\% 27.7 \text { tedavi terk }\end{array}$ \\
\hline (23) & İsveç & $\begin{array}{l}284 \\
\% 81 \\
32.2\end{array}$ & $\begin{array}{l}\text { Internet } \\
\text { Temelli BDT }\end{array}$ & 8 hafta & $\begin{array}{l}3 \\
6 \\
18 \\
36 \\
\text { ay }\end{array}$ & NODS & $\begin{array}{l}\text { HADS } \\
\text { QOLI }\end{array}$ & $\begin{array}{l}\text { Tekrarlanarak } \\
\text { karşıllaştırımalı }\end{array}$ \\
\hline (24) & İsveç & $\begin{array}{l}127 \\
\% 83,5 \\
40.5\end{array}$ & $\begin{array}{l}\text { Motivasyon } \\
\text { el terapi } \\
\text { (MT), BDT }\end{array}$ & $\begin{array}{l}\text { Haftada } 3 \\
\text { saat, } 8 \\
\text { hafta }\end{array}$ & $\begin{array}{l}6- \\
12 \\
\text { ay }\end{array}$ & NODS & $\begin{array}{l}\text { BAl } \\
\text { BDI }\end{array}$ & $\begin{array}{l}\mathrm{MT}=\mathrm{BDT} \\
\% 30 \text { tedavi terk }\end{array}$ \\
\hline (25) & Amerika & $\begin{array}{l}68 \\
\% 62 \\
49.0\end{array}$ & $\begin{array}{l}\text { Duyarsızlaşt } \\
\text { ırma, MT, } \\
\text { Adsız } \\
\text { Kumarbazla } \\
\text { r }\end{array}$ & $\begin{array}{l}8 \text { hafta, } 6 \\
\text { seans }\end{array}$ & 6 ay & $\begin{array}{l}\text { SCI-PG } \\
\text { G-SAS } \\
\text { CGI } \\
\text { PG- } \\
\text { YBOCS }\end{array}$ & $\begin{array}{l}\text { SDS } \\
\text { HAM-A } \\
\text { HAM-D } \\
\text { QOLI }\end{array}$ & $\% 66,7$ azalma \\
\hline (26) & Singapur & $\begin{array}{l}80 \\
\% 92,5 \\
36,7\end{array}$ & BDT & 8 seans & $\begin{array}{l}3, \\
6, \\
12 \\
\text { ay }\end{array}$ & $\begin{array}{l}\text { G-SAS } \\
\text { GRTC } \\
\text { SDS }\end{array}$ & $\begin{array}{l}\text { PWI } \\
\text { HADS } \\
\text { TPQ }\end{array}$ & $\begin{array}{l}\text { Kumara yönelik } \\
\text { değişim isteği } \\
\text { koruyucu }\end{array}$ \\
\hline (27) & İspanya & $\begin{array}{l}440 \\
\% 94,5 \\
41,2\end{array}$ & Grup BDT & $\begin{array}{l}16 \text { hafta, } \\
90 \mathrm{dk}\end{array}$ & $\begin{array}{l}1,3 \\
\text { ay }\end{array}$ & SOGS & $\begin{array}{l}\text { SCL- } \\
90-R \\
\text { TCl-R }\end{array}$ & $\begin{array}{l}\text { \%46,6 Nüks } \\
\% 79,2 \text { 'si ilk } 5 \\
\text { seans } \\
\% 44,5 \text { tedavi terk }\end{array}$ \\
\hline (28) & Amerika & $\begin{array}{l}49 \\
\% 35,7 \\
46,57\end{array}$ & $\begin{array}{l}\text { Bekleme } \\
\text { listesi, } 12 \\
\text { adım terapi, } \\
\text { grup BDT }\end{array}$ & $\begin{array}{l}\text { Haftada } \\
2,8 \text { hafta }\end{array}$ & 6 ay & $\begin{array}{l}\text { SOGS } \\
\text { TLFB }\end{array}$ & $\begin{array}{l}\text { BDI } \\
\text { BAl }\end{array}$ & $\begin{array}{l}\text { Grup terapiler } \\
\text { essit, bekleme } \\
\text { listesinde değişim } \\
\text { yok }\end{array}$ \\
\hline (29) & Norveç & $\begin{array}{l}35 \\
\% 87 \\
32,8\end{array}$ & $\begin{array}{l}\text { BDT, } \\
\text { psikofarmak } \\
\text { oloji }\end{array}$ & 8 hafta & $\begin{array}{l}3,6 \\
\text { ay }\end{array}$ & NODS & $\begin{array}{l}\text { SCID-I } \\
\text { SCID-\|I } \\
\text { BDI }\end{array}$ & $\begin{array}{l}\text { Kısa sürede iki } \\
\text { yaklaşım da etkin }\end{array}$ \\
\hline (30) & Avustralya & $\begin{array}{l}87 \\
\% 50 \\
46.4\end{array}$ & $\begin{array}{l}\text { BDT ve } \\
\text { yüzleştirme }\end{array}$ & 12 hafta & 6 ay & $\begin{array}{l}\text { VGS } \\
\text { GRCS } \\
\text { GUS }\end{array}$ & $\begin{array}{l}\text { K10 } \\
\text { WSAS }\end{array}$ & Eşit sonuçlar \\
\hline (31) & Avustralya & $\begin{array}{l}205 \\
\% 42 \\
39\end{array}$ & BDT & 10 seans & $\begin{array}{l}1, \\
3, \\
6, \\
12 \\
\text { ay }\end{array}$ & VAS & $\begin{array}{l}\text { BDI } \\
\text { BAl } \\
\text { WSAS }\end{array}$ & \%69 iyileşme \\
\hline
\end{tabular}

BAl: Beck Anxiety Inventory; BDI: Beck Depression Inventory; CGI: Clinical Global Impression; GRCS: Gambling Related Cognitions Scale; GRTC: Gambling Readiness to Change Scale; G-SAS: Gambling Symptom Assessment Scale; GUS: Gambling Urge Scale; HADS: Hospital Anxiety and Depression Scale; HAM-A: Hamilton Anxiety Rating Scale; HAM-D: Hamilton Depression Rating Scale; K10: Kessler 10 Scale; MCMI-III: Millon Clinical Multiaxial Inventory; NODS: National Opinion Research Center DSM Screen for Gambling Problems; PG-YBOCS: YaleBrown Obsessive Compulsive Scale Modified for Pathological Gambling; PWI: Personal well-being scale; QOLI: Quality of Life Inventory; SCIPG: Structured Clinical Interview for Pathological Gambling; SDS: Severity of Dependence Scale; SOGS: South Oaks Gambling Scale; TCIR:Temperament and Character Inventory; TLFB: Timeline Follow-back; TPQ: Treatment Perceptions Questionnaire; VAS: Visual Analogue Scale; VGS: Victorian Gambling Scale; WSAS: Work and Social Adjustment Scale.

Araştırma dahilinde incelenen 10 çalışmanın hepsi kumar davranışı yanısıra kumarla ilişkili olabilecek kişilik özellikleri, depresyon, anksiyete gibi psikopatolojik belirtileri de araştırmalarına dahil etmiştir. İkincil sorunlar arasında en fazla incelenen $6(\% 60)$ çalışma ile depresyon ve anksiyetedir. 
İncelenen araştırmalarda ilk 6 ayda nüksün en fazla seviyede görüldüğg̈ gözlemlenirken, yalnız yaşama, yaşam doyumda düşüş, kumara harcanan para gibi demografik değişkenlerin nükse sebep olabileceği görülmüştür. Zarardan kaçınmak, değişime hazır olmak gibi kişisel özellikler tedavi sürecinden kopmayı engellemesi nedeniyle tedavinin etkinliğini artırmıştır.

BDT'nin etkinliği açısından incelenen çalışmaların hemen hepsinde kullanılan BDT tekniğinin kısa süreli terapi yöntemi olarak etkin olduğu, fakat tüm çalışmalarda yaklaşık \%30 oranında tedavinin terk edildiği görülmüştür. Çalışmalarda kullanılan tekniğin ne olduğu farklılık göstermeksizin kontrol gruplarına oranla terapi uygulanan gruplar kumar oynama davranışını azaltmış ve nüks gecikmiştir.

\section{Tartışma}

İncelenen on çalışma ile KOB'da uygulanan BDT tekniklerinin etkinliği derlenmiştir. Gerek KOB'da terapinin ne derece koruyucu ve tedavi edici olduğu gerekse diğer psikolojik rahatsızlıkların bu çalışmalarda ne derece dahil edildiği bu derlemede toplanmıştır. KOB tedavisinde farklı psikoterapi yöntemlerinin kullanılabileceği belirtilmektedir (11). Buna rağmen, BDT'nin KOB tedavisinde diğer yaklaşımlara göre daha etkin olduğu bilinmektedir (32).

Çalışmada yer alan tüm araştırmalarda BDT tekniklerinin her birinde ortalama 6 aylık bir takip süreci bulunmaktadır. Bu çalışmaların özellikle kısa süreli uygulamarla etkili olduğu ve kısa-orta süreli çözüm sağladığı görülmektedir. Bu bulgular alanyazında da benzer şekilde yer almıştır. Şöyle ki, BDT'nin kısa ve orta süreli tedavide etkili olduğu bilinmektedir $(33,34)$. Bağımlıı̆ın tedavisi yazılan kuramsal açıklamalar, bağımlııkta nüks süresinin uzamasının ve bağımlıık olmadan süren bir yaşama devam etmenin başarıı bir tedavi olduğunu belirtmektedir (35). Araştırmaya dahil edilen çalışmalarda BDT tekniği ile terapi alan katılımcıların kontrol grubunda olan katılımcılara göre daha düşük kumar oynama arzusu yaşamaları ve daha düşük nüks oranlarına sahip olmaları BDT'nin KOB üzerinde etkinliğini kanıtlar niteliktedir.

Araştırmada incelenen çalışmaların her birinde çeşitli BDT teknikleri uygulanmış, ve tüm çalışmalarda KOB ile ilişkili davranışlarda bu yaklaşımların olumlu bir etkisi olduğu gözlemlenmişsir. Her ne kadar tüm yöntemlerin etkisi olduğuna dair bulgular olsa da araştırmaya dahil edilen tüm katılımcılar gönüllülük esasıyla çalışmaya katılı̆̆ı unutulmamalıdır. İncelenen çalışmaların sonuçlarında da yer aldığı üzere değişime açıklık kumara nüksü engelleyen, koruyucu faktörlerden biridir (26). Bu yüzden ileriki çalışmalarda tedavi arayışında olmayan KOB olan bireylerin tedavisi alanında neler yapılabileceğine ağırlık vermeleri gerektiği düşünülmektedir.

Ülkemizde KOB ile ilgili yapılan klinik tedavi araştırmaları olgu sunumları (36-38) ve derleme çalışmaları (39) ile sınırlı olması nedeni ile, Türkçe alanyazında KOB tedavisine yönelik çalıșmaların az olduğu düşünülmektedir. KOB tedavisine yönelik Türkçe alanyazın incelendiğinde psikofarmakolojik tedavilerin etkin olduğunu gösteren derlemeler (40) ve yine BDT'nin tedavide etkili olduğuna yönelik kuramsal kaynaklar (39) mevcuttur.

\section{Sonuç}

Bu sistematik derleme, kumar bozukluklarındaki kullanılan BDT tekniklerinin tedavideki etkinliğini araştırmıştır. Araştırma sonuçları ile birlikte gelecekteki tedavi çalışmaları ve araştırmalara, BDT teknikleriyle yapılmış çalışmaları derleyerek Türkçe alanyazına bir ışık tutmak hedeflenmiştir.

Çalışma sonuçlarına göre BDT tekniklerinin KOB tedavisinde ve KOB ile ilişkili diğer psikopatolojik belirtilerin azalmasında etkili olduğu görülmüştür. Araştırmaların hepsinde nüks ve tedavi terkine dair çalışmalar da dahil edilmiş olup bu çalıșmalada birbirinden farklı sonuçlar gözlemlenmiştir. Tüm bu sonuçlardaki farkılıklar gözönüne alındığında tedavinin etkinliğine dair KOB'da standartlaştııımış bir tedavi süreci olmadığı görülmüştür. Gerek tedavinin karmaşık bir süreç olması, gerekse KOB'da diğer bağımlılıkardan farklı olarak özbilidirime dayalı bir ölçüm yapılması tedavilerin etkinliğini değerlendirmeyi zorlaştırmaktadır. Bunlar göze alındığında standartlaştırımış bir tedavi protokolü ve ölçüm aracının olması 
gerektiği düşünülmektedir. Çalışmada yer alan araştırmaların ortak yönleri olduğu kadar farklı yöntem ve ölçüm araçlarıyla değerlendirme yapması bu çalışmalardan daha etkili olan yöntemi bulmayı engellemektedir.

Önceki incelemelere göre, BDT'nin kumar davranışlarını azaltmadaki rolü cesaret verici ve iyimser, belki de sorunun zorluğu göz önüne alındığında, beklenenden daha fazla olduğu görülmüştür. Bununla birlikte, uzun dönem takip verileri ile büyük ölçekli iyi kontrollü tedavi çalışmalarının yokluğu da dikkate alınmalıdır. Bu bilgilerle bile, kumarla ilgili sorunları olanların büyük çoğunluğunun yardım istemediği sorunun ele alınması gerekmektedir. Bu konulara rağmen, BDT tekniklerinin KOB tedavisinde faydalı olduğuna dair çalışma bulguları mevcuttur.

\section{Kaynaklar}

1. Stucki S, Rihs-Middel M. Prevalence of adult problem and pathological gambling between 2000 and 2005: An update. J Gambl Stud 2007; 23(3): 245-257.

2. Meyer G, Hayer T, Griffiths M. Problem Gambling in Europe: Challenges, Prevention, and Interventions. New York, NY: Springer, 2009.

3. American Psychiatric Association. Diagnostic and Statistical Manual of Mental Disorders, DSM-III. Washington, DC: American Psychiatric Association, 1980.

4. American Psychiatric Association. Diagnostic and Statistical Manual of Mental Disorders, DSM-IV. Washington, DC: American Psychiatric Association, 2000.

5. American Psychiatric Association. Diagnostic and Statistical Manual of Mental Disorders, DSM-5. Washington, DC: American Psychiatric Association, 2013.

6. Abbott MW, Volberg RA, Rönnberg S. Comparing the New Zealand and Swedish national surveys of gambling and problem gambling. J Gambl Stud 2004; 20(3): 237-258.

7. Suurvali H, Hodgins D, Toneatto $T$, Cunningham J. Treatment seeking among Ontario problem gamblers: Results of a population survey. Psychiatr Serv 2008; 59(11): 1343-1346.

8. Rizeanu S. Pathological gambling treatment-review. Procedia Soc Behav Sci 2015; 187: 613-618.

9. Ledgerwood DM, Petry NM. Current trends and future directions in the study of psychosocial treatments for pathological gambling. Curr Dir Psychol Sci 2005; 14(2): 89-94.

10. Pallesen S, Mitsem M, Kvale G, J et al. Outcome of psychological treatments of pathological gambling: a review and meta-analysis. Addiction 2005; 100(10): 1412-1422.

11. Toneatto T, Ladouceur R. Treatment of pathological gambling: a critical review of the literature. Psychol Addict Behav 2003; 17(4): 285-292.

12. Petry NM. Pathological Gambling: Etiology, Comorbidity, and Treatment. Washington, DC: American Psychological Association, 2005.

13. Smith GJ, Hodgins D, Williams R. Research and Measurement Issues in Gambling Studies. Amsterdam: Emerald Group, 2007.

14. Walker MB. Problems in measuring the effectiveness of cognitive therapy for pathological gambling. J Gambl Stud 2005; 21(1): 79-90.

15. Gooding P, Tarrier N. A systematic review and meta-analysis of cognitive-behavioural interventions to reduce problem gambling: Hedging our bets? Behav Res Ther 2009; 47(7): 592-607.

16. Tolchard B, Battersby MW. Cognitive behaviour therapy for problem gamblers: A clinical outcomes evaluation. Behav Change 2013; 30(1): 12-23.

17. Hodgins DC, Peden N. Cognitive-behavioral treatment for impulse control disorders. Braz J Psychiatry 2008; 30(Suppl. 1): 31-40.

18. Petry NM. Gamblers anonymous and cognitive-behavioral therapies for pathological gamblers. J Gambl Stud 2005; 21(1): 27-33.

19. Chretien M, Giroux I, Goulet A, et al. Cognitive restructuring of gambling-related thoughts: A systematic review. Addict Behav 2017; 75: 108-121.

20. Swan JL, Hodgins DC. Brief interventions for disordered gambling. Can J Addict 2015 ;6(2): 29-36.

21. Liberati A, Altman DG, Tetzlaff J, et al. The PRISMA statement for reporting systematic reviews and metaanalyses of studies that evaluate health care interventions: explanation and elaboration. PLoS Med 2009; 6(7): e1000100. 
22. Aragay N, Jiménez-Murcia S, Granero R, et al. Pathological gambling: Understanding relapses and dropouts. Compr Psychiatry 2015; 57: 58-64.

23. Carlbring P, Degerman N, Jonsson J, Andersson G. Internet-based treatment of pathological gambling with a three-year follow-up. Cogn Behav Ther 2012; 41(4): 321-334.

24. Carlbring $\mathrm{P}$, Jonsson J, Josephson $\mathrm{H}$, Forsberg L. Motivational interviewing versus cognitive behavioral group therapy in the treatment of problem and pathological gambling: a randomized controlled trial. Cogn Behav Ther 2010; 39(2): 92-103.

25. Grant JE, Donahue CB, Odlaug BL, Kim SW. A 6-month follow-up of imaginal desensitization plus motivational interviewing in the treatment of pathological gambling. Ann Clin Psychiatry 2011; 23(1): 3-10.

26. Guo S, Manning V, Thane KKW, et al. Predictors of treatment outcome among Asian pathological gamblers (PGs): clinical, behavioural, demographic, and treatment process factors. J Gambl Stud 2014; 30(1): 89-103.

27. Jiménez-Murcia S, Granero R, Fernandez-Aranda F, et al. Predictors of outcome among pathological gamblers receiving cognitive behavioral group therapy. Eur Addict Res 2015; 21(4): 169-178.

28. Marceaux JC, Melville CL. Twelve-step facilitated versus mapping-enhanced cognitive-behavioral therapy for pathological gambling: A controlled study. J Gambl Stud 2011; 27(1): 171-190.

29. Myrseth H, Molde H, Støylen IJ et al. A pilot study of CBT versus escitalopram combined with CBT in the treatment of pathological gamblers. Int Gambl Stud 2011; 11(1): 121-141.

30. Smith DP, Battersby MW, Harvey PW, et al. Cognitive versus exposure therapy for problem gambling: Randomised controlled trial. Behav Res Ther 2015; 69: 100-110.

31. Tolchard B, Battersby M. Treatment completion in a cognitive behaviour therapy service for problem gamblers: Clinical outcome study. J Addict Res Ther 2013; 4(5): 1-7.

32. Tarrier N. Case Formulation in Cognitive Behaviour Therapy: The Treatment of Challenging and Complex Clinical Cases. London: Routledge, 2006.

33. Cowlishaw S, Merkouris S, Dowling N. Psychological therapies for pathological and problem gambling. Cochrane Database Syst Rev. 2012; 11: CD008937.

34. Yip SW, Potenza MN. Treatment of Gambling Disorders. Curr Treat Options Psychiatry. 2014; 1(2): 189-203.

35. Marlatt GA, Donovan DM. Relapse Prevention: Maintenance Strategies in the Treatment of Addictive Behaviors. New York: Guilford Press, 2005.

36. Güriz S0, Ekinci A, Türkçapar MH. Bir patolojik kumar hastasının bilişsel davranış̧̧ı terapisi. Bilişsel Davranışçı Psikoterapi ve Araştırmalar Dergisi. 2012; 1: 105-112.

37. Derin S, Bilge F. Patolojik kumar oynama: Bir olgu sunumu. Demirel Ö, Dinçer S (editors). Küreselleşen Dünyada Eğitim. Ankara: Pegem Akademi, 2017: 485-494.

38. Geniş B, Hakan AK. İntihar girişimi ile acil servise başvuran kumar bağımlıı̆ı olgusu. Bağımlılık Dergisi 2020; 21(1): 92-98.

39. Çakmak S, Tamam L. Kumar oynama bozukluğu: Genel bir bakış. Bağımlılık Dergisi 2018; 19(3): 78-97.

40. Uğurlu TT, Şengül CB, Şengül C. Bağımlılk psikofarmakolojisi. Psikiyatride Güncel Yaklaşımlar 2012; 4(1): 37 50. 